\title{
The Effect of Social, Economic and Cultural Variables on the Lack of Interest in Liability Insurance in "Case Study» of Sanandaj
}

\author{
Shafei Reza, Eftekhar Azadeh. \\ Department of Management, Islamic Azad University, \\ Sanandaj Branch, Sanandaj, Iran \\ Email: azadeh.eftekhar65@gmail.com
}

Keywords: Economic Factors, Social Factors, Cultural Factors, Liability insurance, Sanandaj.

\begin{abstract}
This article was done with the aim of surveying the effect of social, economic and cultural variables on the lack of interest in liability insurance (responsibility) of Sanandaj. This study is a kind of practical research and it's also descriptive with the correlation method of information collection (amassment). The statistic society of the research is all of the engineers, doctors and contractors of Sanandaj that don't use the liability insurance. They were about 650 persons which according to the limitation of statistic society checking (scrutiny), 250 persons were chosen by the random sampling which finally 241 persons took place in the research process. For research data collection, the substantiated questionnaire consisted of 24 locutions and 3 cultural, economic and social scales (criterions) was used based upon the Likret's five-point spectrum. According to the analysis of collected data, the results showed that the economic and cultural factors have a negative effect on the liability insurance, and totally with the cultural and economic condition increment, the lake of interest in liability insurance will decrease.
\end{abstract}

\section{INTRODUCTION}

The activities of insurance companies are so important, regarding to the daily expansion (increment) of economic and social activities and countries development. Whatever countries take fundamental steps in the terms of development, the insurance industry will have more desirable place in these countries; specially the field of the civil liability insurance; which devotes and assigns the appropriate portion of insurance market to itself in these countries. This kind of insurance doesn't find its own suitable portion and place in our country's market. In order to determine and identify this kind of insurance to the society people, informing and advertising can have a prominent and visible role as an important proposed communicational tool. The advertisement and information improve the process of economic and social growth of society, and can have positive and negative roles (effects) in different matters and based on how they're used; they cause success and failure in various activities. So in this regard, the current article was done in the field of civil insurances liability, and the liability discussion was transformed from a bilateral topic to a fourways topic (discussion). Therefore liability is one of the most complicated terms which besides the juridical contents, it's an important parameter in developing the quantitative and qualitative surfaces of social welfare in societies. The reasons of this speech are stable (proved) on the principle that anyone in the current world regarding to the extensive activity branches causes some benefits or welfare for some other people and losses or damages for some others during the performance of their duties. As result of these losses and damages in the first phase, someone will directly damage and definitely with complicating the active community rings, there are some other people whom will be damaged from the first person's detriment. So it can be daresay that in the current era, the liability is not just a term with the restricted dimensions but it's as a factor which completely affects the societies through the direct transmission of its influences and consequences on the social welfare (Ameli, 2003).

In this framework, the insurance also in the context of countries economics regarding to the providing role and the appropriate covers for decreasing the dangerous loads of people to the beneficiary insurer and profiting from these risky operations can introduce a special kind of 
insurance to the world as civil liability insurance. Probably in the early of this field creation, the only existence mentality was covering the restricted and bilateral liabilities (responsibility), but synchronous with the human knowledge complexity, the field also get complicated. Nowadays, simultaneous with the development degree, the condition and design of laws and executive warranties of countries laws increase the liability insurance penetration. So that a unit formula can be presented for this definition as follows:

$<<$ Whatever the societies get more developed and their laws also get more acceptable and detailed in the terms of design, then the liability insurances will also get more developed and utilized. $>>$ So, one of the most important factors in the degree (level) of liability insurances development is existing the useful and auto-set laws and powerful executive warranties for them. The statistic surveys show that in comparison with the other insurance fields, the liability insurance has lower portion in insurance Market (Ameli, 2003). According to the civil liability theory and based on the (Fault theory) person is liable whenever that she/he is committed a fault or mistake in her/his own activities. The fault is consisting of \{infringement and aggression\}. The aggression means abandoning a work that leads to the contract or law of secular law for preserving the unnecessary property. The infringement means exceeding from the allowed or standard range toward the other's right and property. According to the civil liability theory based on $<<$ the theory of danger $>>$, committed a fault is not the condition of civil liability, but anyone who makes mistake (dangerous move) in their own activities and causes disadvantages or damage for other people is liable and responsible. According to the theory of right guarantee, any person has right to live a secure and healthy life in society and her/his rights should be ensured. So as soon as the right has gone or wasted, losses factor (person) should compensate it (Parsamehr, 2002). Regarding to the top matters, the research is up to answer the question that: how much the social, economic and cultural variables affect the lake of interest in liability insurance?

\section{THEORETICAL BASIS}

\subsection{Liability and Liability Insurance}

Liability: the liability means that the legal or actual person takes responsibility of the harmful effects and consequences of his/her act and compensate the incurred damage. The subject of liability insurance: the subject of liability is provide and compensate the damages that happens to others by the organizations, businesses and people's acts and activities, this feature of commitment for the benefit of others (third parties) is the feature of this kind of insurance (Ahmadi, 2012).

The differences between retributive and civil liability: it's that the retributive liability is created when that a person or persons dis-adjust the discipline of the society and cause damage and harm for it by their acts and behaviours. Therefore, the realization of legal liability is related to damage the person or society, with this regard that criminal liability of the incurred damage is measured out to the society. While that in civil liability, the incurred damage to the society is not considered but the personal harm or damage of the person is important and it should be known that this harmful action can cause damage for both the person and society.

According to the civil liability theory and based on the (Fault theory) person is liable whenever that she/he is committed a fault or mistake in her/his own activities. The fault is consisting of \{infringement and aggression\}. The aggression means abandoning a work that leads to the contract or law of secular law for preserving the unnecessary property. The infringement means exceeding from the allowed or standard range toward the other's right and property. According to the civil liability theory based on $<<$ the theory of danger $>>$, committed a fault is not the condition of civil liability, but anyone who makes mistake (dangerous move) in their own activities and causes disadvantages or damage for other people is liable and responsible. According to the theory of right guarantee, any person has right to live a secure and healthy life in society and her/his rights 
should be ensured. So as soon as the right has gone or wasted, losses factor (person) should compensate it (Parsamehr, 2002).

Actually, the civil liability is realized when that there be the damaged or detriment person and acclaim his/her assumpsit. The civil liability subject is considered when that there are two persons that one of them is the damage factor and another is lost (damaged) and a discord or subject take has taken place which should be solved. Therefore, the liable means someone who is responder to others, and the person is liable based on the civil dimensions whenever that the person has to compensate the damage depend on the social laws and conventions, but sometimes the persons are liable and have civil liability due to the actions and activities or even abandoning an act; and sometimes for presiding persons or family members and even the people that they superintend or the property and appurtenant things which are deposited to them (Mahmud Salehi, 1993). On the other hands, whenever the person has to compensate the incurred damage to another person, $\mathrm{s} / \mathrm{he}$ is traditionally liable to him/her. Also in society means that persons should respond for some of their own acts and in a case that a loss or damage is caused due to another person's fault and carelessly and the factor of the event has to compensate the damage, it's said that the person has a civil liability toward them, and in the other hands has guaranteed the incurred damage and should be provided (Drodian, 1997).

\subsection{Marketing and the Sales of Liability Insurance}

Nowadays with the increment of competition level in various universal and internal markets, using the marketing strategies for better selling the products is notified. So that if a company has powerful marketing network, it can guide the company to the lofty (high) peaks of profitability besides earning more market sharing and portion. At the moment, with the abundant complexity and expansion of marketing role in the survival of active companies in different markets, the marketing matter has gotten such important place that so many companies are specially acting out in very particular fields about marketing activities for their productive companies. The surveys showed that the failure of companies are because their disability in operating the marketing strategies. These companies are ignoring the market evolutions and the changes of customers' consumption pattern, and instead of doing advancement marketing, they proceed to sale and prefer the more profitability to customers' satisfaction. Overall, the marketing is consisted of: meeting the customer's needs (with the right perception of their needs) and the process of needs satisfaction and people's demand. It's obvious that the customers' need in purchasing and consuming and services which is related to the marketing is deposited and hided in the quality, satisfaction and value of productions (goods). So in marketing operation, the following elements should be done carefully: \{the recognition of market, market measurement, marketing strategies, portfolio, market-making, sales talk and finally selling, in the marketing environment which is consisted of actors and all effective powers on the company performance that are the purpose for creating and preserving a successful trade and communicating with market. In such condition, precise determination of the effective factors can definitely improve the effectiveness of marketing. Totally the effective factors on marketing environment can be described and introduced as follows:

1. Political and juridical factors

2. Social and cultural factors

3. Economic factors

4. Demographics factors

5. Physical factors

6. Technological factors

Among different kinds of marketing of service production, insurance is one of the high professional fields of marketing. In the marketing (process), the service production because of (following elements) it has complexity and high value: invisibility of services (means that the service cannot be seen, touched or even felt before, after and in the time of purchasing), dissimilarity and 
discontinuity of services (the quality of services are often different and discontinuous, services are depended on the person that present them. Besides, quality of services is depended on the factors like the presenters of services, time of presentation, and its place etc.), inseparability of services (the services cannot be separated from the person who present it) and non-maintenance of services (unlike the productions, services cannot be stored in the stock room and sold after a while. When demands are increased in a period of time, because of non-maintenance feature of services, it cannot be stored before presenting in such periods and it causes problems and issues) (Ahmadi, 2012).

\section{RESEARCH METHOD, SOCIETY AND STATISTIC SAMPLE, SAMPLING METHOD AND ANALYSIS OF DATA:}

In the regard that this article can be used in decisions about the management system of insurance, so it's a kind of practical researches and also in this regard that it's trying to survey and study the available truths and responding to questions about the current situation, therefore it's (considered) as a descriptive research and with the correlation method. The statistic society of the research is all of the engineers, doctors and contractors of Sanandaj that don't use the liability insurance. They were about 650 persons which according to the limitation of statistic society checking (scrutiny), 250 persons were chosen by the random sampling which finally 241 persons took place in the research process. For research data gathering, the substantiated questionnaire consisted of 24 locutions and 3 cultural, economic and social scales (criterions) was used based upon the Likret's five-points spectrum. For data analysis, the correlation coefficient of Pearson and Regression analysis was used.

\section{RESULTS}

4.1. Hypothesis (1): There is a relationship between the social conditions of Sanandaj's citizens with their lack of interest in liability insurance.

Table (1): The results of Pearson's correlation coefficient about relationship between the social conditions of Sanandaj's citizens with their lack of interest in liability insurance

\begin{tabular}{|c|c|c|}
\hline $\begin{array}{c}\text { The Lack of Interest in } \\
\text { Liability Insurance }\end{array}$ & $\begin{array}{c}\text { Amount of Pearson } \\
\text { Correlation }\end{array}$ & Significance Level \\
\hline $\begin{array}{c}\text { The Social Condition of } \\
\text { Citizens }\end{array}$ & $-0 / 093$ & $0 / 121$ \\
\hline
\end{tabular}

According to the results of table (1), the research hypothesis is rejected in significance level of $0 / 05$, and so there isn't a significance relationship between the social conditions of Sanandaj's citizens with their lack of interest in liability insurance.

4.2. Hypothesis (2): There is a relationship between the economic conditions of Sanandaj citizens with their lack of interest in liability insurance.

Table (2): The results of Pearson's correlation coefficient about relationship between the economic conditions of Sanandaj citizens with their lack of interest in liability insurance

\begin{tabular}{|c|c|c|}
\hline $\begin{array}{c}\text { The Lack of Interest in } \\
\text { Liability Insurance }\end{array}$ & $\begin{array}{c}\text { Amount of Pearson } \\
\text { Correlation }\end{array}$ & Significance Level \\
\hline $\begin{array}{c}\text { The Economic Condition of } \\
\text { Citizens }\end{array}$ & $-0 / 524$ & $0 / 000$ \\
\hline
\end{tabular}

According to the results of table (2), the research hypothesis is accepted in significance level of $0 / 05$, and so there is a significance relationship between the economic conditions of Sanandaj citizens with their lack of interest in liability insurance. The significance level is $0 / 524$ and in the 
reverse direction, it means that as the economic condition of citizen get better, the lack of interest in liability insurance will also decrease.

4.3. Hypothesis (3): There is a relationship between the cultural conditions of Sanandaj citizens with their lack of interest in liability insurance.

Table (3): The results of Pearson's correlation coefficient about relationship between the cultural conditions of Sanandaj citizens with their lack of interest in liability insurance

\begin{tabular}{|c|c|c|}
\hline $\begin{array}{c}\text { The Lack of Interest in } \\
\text { Liability Insurance }\end{array}$ & $\begin{array}{c}\text { Amount of Pearson } \\
\text { Correlation }\end{array}$ & Significance Level \\
\hline $\begin{array}{c}\text { The Economic Condition of } \\
\text { Citizens }\end{array}$ & $-0 / 218$ & $0 / 009$ \\
\hline
\end{tabular}

According to the results of table (3), the research hypothesis is accepted in significance level of $0 / 05$, and so there is a significance relationship between the cultural conditions of Sanandaj citizens with their lack of interest in liability insurance. The significance level is $0 / 524$ and in the reverse direction, it means that as the cultural condition of citizen get better, the lack of interest in liability insurance will also decrease.

\section{- Regression}

The Regression aims to measure the effect of any independent variables on the dependent variables and estimate the dependent variables and also determine the portion of any independent variables in specifying the dependent variables.

The acting method of Regression is so that at first, the significance of whole Regression model should be testified, then the significance of each coefficient of variables should be individually testified and surveyed.

\section{Simultaneous Regression}

In the method of Simultaneous Regression, all independent variables are simultaneously put in the model and have been analysed. For the main questions of test in research, the Regression is used.

\subsection{The Main Question of Research: How much is the influence level of each social, cultural and economic factors on the lack of interest in liability insurance in citizens of Sanandaj?}

Table (4): Summary of Regression Model

\begin{tabular}{|l|l|l|l|l|}
\hline $\begin{array}{l}\text { The Regression } \\
\text { Model }\end{array}$ & $\mathrm{R}$ & $\mathrm{R} 2$ & Modified R2 & Watson Camera \\
\cline { 2 - 5 } & $0 / 758$ & $0 / 575$ & $0 / 572$ & $2 / 202$ \\
\hline
\end{tabular}

According to the results of table (4), the coefficient of model determination is $0 / 575$ which it means that $0 / 575$ of changes are specified from the lack of interest in liability insurance by economic and cultural factors.

One of the premises which is considered in Regression is the faults independence (the difference between the actual numbers and pre-estimated numbers). If the theory of faults independence is being rejected and the faults doesn't have correlation (integration) together, there won't be possibility to use Regression. The level (amount) of the test is measured in table (5). As the statistics are between the ranges of $1 / 5$ to $2 / 5$, so it can be concluded that the faults are independent and Regression model can be used. 
Table (5): The practise Results of Regression Model

\begin{tabular}{|c|c|c|c|c|}
\hline & $\begin{array}{c}\text { Freedom degree } \\
(\text { level })\end{array}$ & $\begin{array}{c}\text { The Average of } \\
\text { Quadrangles }\end{array}$ & $\mathrm{F}$ & $\begin{array}{c}\text { Significance } \\
\text { Level }\end{array}$ \\
\hline Regression & 3 & $14 / 813$ & $171 / 466$ & $0 / 000$ \\
\hline Reminder & 380 & $0 / 086$ & - & - \\
\hline Total & 383 & - & - & - \\
\hline
\end{tabular}

The above table shows the significance (meaning) of whole Regression model:

H0: The Regression is not meaningful: $\beta 1=\beta 2=0$

H1: The Regression model is meaningful. So, it means that at least one of the independent variables has linear relation (connection) with the dependent variable.

According to the measured level of significance, zero hypothesis is rejected. Therefore the hypothesis of Regression model significance is confirmed and at least one of the independent variables has linear relation (connection) with the dependent variable.

Table (6): The Results of multiple Regression Model

\begin{tabular}{|c|c|c|c|c|}
\hline $\begin{array}{c}\text { Predictor } \\
\text { Variables }\end{array}$ & $\mathrm{B}$ & Beta & $\mathrm{T}$ & $\begin{array}{c}\text { Significance } \\
\text { Level }\end{array}$ \\
\hline Constant Value & $1 / 064$ & - & $10 / 751$ & $0 / 000$ \\
\hline Economic & $-0 / 22$ & $-0 / 588$ & $-5 / 46$ & $0 / 000$ \\
\hline Cultural & $-0 / 341$ & $-0 / 327$ & $-0 / 51$ & $0 / 017$ \\
\hline
\end{tabular}

Table (6) shows the standard and non-standard coefficients of each kinds variables of the model and surveys the significance of these coefficients. The amount of Beta shows the partial importance of independent variables between the dependent variables. So the effect of economic factors in the lack of interest in liability insurance is $0 / 588$ and also influence it in reverse direction and the effect of cultural factors in the lack of interest in liability insurance is $0 / 588$ and also influence it in reverse direction.

\section{DISCUSSION AND CONCLUSION:}

Liability insurances are a kind three main branches of insurance and located along with the property and individuals insurances. According to the subject of this insurance, the incurred damage which is taken place to the third parties that is created due to an act or unpremeditated abandoning of an activity is being compensated in both parts the financial and bodily damages. The risk evaluation of liability insurances is sometimes more sensible and complicated from the risk measurement in property and individuals insurances because of juridical, social and technical matters, and in developed laws and societies, the insurers are encountered with the increment of damage coefficient in this field of insurance. The economic, social and cultural development process make the use of these liability insurances and accompaniment of this field (major) an essential and necessary matter along with the process of development, and in this regard, providing the legal bases, determining the restriction and limitation of civil liabilities of individuals (people) and preparing and editing different kinds of liability insurances with technical and practical methods and danger evaluation have a special importance (Riahi Frokhami, 2002). Culture and culture-making are the base and root of any activity development such as economic activities. The insurance industry as one of the basic and important part in each country's economic, it can develop and grow when that there be the culture and its using (function) between the people. Nowadays in many of development countries (of economic), the costs which is related to the insurance are 
constituted made an important and significance percent of individuals and organizations costs. But why in our country, the insurance constitute a very low percent of person's costs so that if we eliminate the compulsory parts such as medical and third party insurances, our country's cost capitation of insurance will be very low. Various factors are partaken in lake of growth and development in Iran's insurance industry. This article is done to survey the mentioned effective factors in the topic which regarding to the analysis of the gathered data, the results showed that the economic and cultural factors have a negative effect on the lack of interest in liability insurance, and totally with increment of economic and cultural conditions, the lack of interest in liability insurance will decrease, and the results of the research have directly a parallelism with researches of Golger (2009) and Dr. Fallah (2001).

\section{References}

[1] Ahmadi, N (2012). The dependency estimation of profession liability insurance demands of doctors in Iran. The journal of insurance industry. $25^{\text {th }}$ year. Number 1, number 97. Page 129 to 155 .

[2] Parsa Mehr, T (2002). Survey the effect of liability insurance on the development of nonpetro exportation in Iran. The Research-paper magazine of insurance. Number 66. Page 139 to 150 .

[3] Dr. Fallah, K (2001). Survey and role of laws and rules proficiency and guarantees in liability insurance development in Iran. The Research-paper magazine of insurance. Number 68. Page 19 to 40 .

[4] Drodian, A (1997). The determination of effective factors on life insurances in Iran's insurance industry. The journal of insurance industry. Number 45. Page 75 to 81 .

[5] Riahi Frokhami, H (2002). Analysis survey of effective factors on the insurance culture development and expansion in society. The Research-paper magazine of insurance. Number 73. Page 95 to 114.

[6] Amili, A. (2003). The role of announcement and advertisement in identifying the correct civil liability insurance for insurers. The Research-paper magazine of economic. Number 9. Page 161 to 190.

[7] Mahmood Salehi, A. (1993). Survey the place of insurance industry in capital economic and market of Iran. The journal of insurance industry. $25^{\text {th }}$ year. Page 165 to 199.

[8] Gogler, M. (2009). Commercial banking, insurance and economic growth in Sweden between 1830 and 1998. Accounting, business and financial history. 19(1), page 21 to 38. 